\title{
Akurasi Fine Needle Aspiration Biopsy sebagai Prosedur Diagnostik Nodul Tiroid di Laboratorium Patologi Anatomi Rumah Sakit Umun Pusat DR M Djamil Padang
}

\author{
Suci Rahmadhani ${ }^{1}$, Aswiyanti Asri ${ }^{2}$, Tofrizal ${ }^{3}$
}

\begin{abstract}
Abstrak
Nodul tiroid dapat disebabkan oleh suatu neoplasma ataupun bukan neoplasma/non neoplasma. Salah satu pemeriksaan awal dalam mendiagnosis nodul tiroid adalah Fine Needle Aspiration Biopsy (FNAB). Teknik FNAB aman, murah, dan risiko komplikasi kecil. Tujuan penelitian ini adalah menentukan akurasi FNAB sebagai prosedur diagnostik nodul tiroid di Laboratorium Patologi Anatomi RSUP Dr M Djamil Padang. Penelitian ini adalah studi analitik dengan metode uji diagnostik menggunakan data sekunder pasien dengan nodul tiroid di RSUP Dr M Djamil Padang. Hasil penelitian menunjukkan terdapat 45 kasus pasien nodul tiroid dengan pemeriksaan FNAB dilanjutkan dengan pemeriksaan histopatologi hasil operasi. Dibandingkan dengan pemeriksaan histopatologi sebagai baku emas, menunjukkan bahwa akurasi FNAB adalah sebesar $62,2 \%$ dengan sensitifitas $61,2 \%$, spesifisitas $62,5 \%$, nilai prediksi positif $75 \%$, nilai prediksi negatif $47,6 \%$. Pada pemeriksaan FNAB didapatkan akurasi yang rendah, maka diperlukan pemeriksaan histopatologi dalam menegakkan diagnosa nodultiroid secara akurat. Simpulan penelitian ini adalah FNAB dapat digunakan sebagai sarana diagnostik preoperatif nodul tiroid, tetapi bukan sebagai pengganti diagnosis histopatologi yang masih menjadi diagnosa pasti untuk nodul tiroid.
\end{abstract}

Kata kunci: FNAB, akurasi, histopatologi, nodul tiroid

\begin{abstract}
Thyroid nodules can be caused by a neoplasm or non neoplasm. One of the earliest examinationto diagnose thyroid nodules is the Fine Needle Aspiration Biopsy (FNAB). This techniques are safe, cheap, and has low risk of complications. The objective of this study was to determine the accuracy of FNAB as a diagnostic procedure of thyroid nodule in Anatomical Pathology Laboratory of Dr M Djamil Padang Hospital. This research was analytic research with diagnostic test method using secondary data of patient with thyroid nodule at Dr M Djamil Padang Hospital. The results showed there were 45 cases of thyroid nodule patients with FNAB examination followed by histopathologic examination. Compared to histopathological examination as gold standard, it shows that FNAB accuracy is $62.2 \%$ with $61.2 \%$ sensitivity, $62.5 \%$ specificity, $75 \%$ positive predictive value, $47.6 \%$ negative predictive value. At the FNAB examination obtained low accuracy, so histopathologic examination is required in the diagnosis of thyroid nodule accurately. The conclusion of this study is that FNAB can be used as a preoperative diagnostic tool for thyroid nodule, but not as a substitute for histopathologic diagnosis which is still a definitive diagnosis for thyroid nodule.
\end{abstract}

Keywords: FNAB, accuracy, histopathology, thyroid nodule.

Affiliasi penulis: 1. Prodi Kedokteran Fakultas Kedokteran Universitas Andalas Padang (FK Unand, 2. Bagian Patologi Anatomi FK Unand, 3. Bagian Patologi Anatomi FK Unand Korespondensi: Suci Rahmadhani, Email: sucirahmadhani72@yahoo.com Telp: 081262030163

\section{PENDAHULUAN}

Kelenjar tiroid merupakan kelenjar endokrin yang paling besar pada tubuh manusia. Sekitar 2-6\% nodul tiroid bisa ditemukan saat pemeriksaan fisik (palpasi daerah leher), sekitar $19-35 \%$ bisa ditemukan 
saat pemeriksaan ultrasonografi dan $8-65 \%$ pada hasil autopsi. ${ }^{1}$ Angka nodul yang ganas $5-15 \%$. Nodul tiroid lebih banyak ditemukan pada wanita. ${ }^{2}$

Nodul tiroid dapat disebabkan oleh suatu neoplasma ataupun bukan neoplasma/non neoplasma. Etiologi terbanyak dari nodul tiorid adalah non neoplasma. Non neoplasma tiroid adalah nodul tiroid yang disebabkan oleh adanya kista tiroid, adenomatous goiter ataupun tiroiditis. Angka kejadian neoplasma tiroid adalah sekitar 2-4\% dari semua nodul tiroid. ${ }^{3}$ Neoplasma atau tumor tiroid dapat berupa tumor jinak ataupun tumor ganas. Nodul jinak berupa adenoma, kista dan tiroiditis yang prevalensinya $90 \%$ dari semua kasus neoplasma. ${ }^{4}$

Tumor ganas atau karsinoma tiroid adalah keganasan yang paling banyak ditemukan pada sistem endokrin. ${ }^{5}$ Angka kejadian karsinoma tiroid sekitar 3,4 $\%$ dari seluruh jenis karsinoma di dunia. ${ }^{6}$ Perbandingan kejadian pada wanita dan pria berkisar $3: 1 .^{7}$ Menurut Perhimpunan Dokter Spesialis Patologi Anatomi Indonesia dalam Ramli (2005), karsinoma tiroid menempati urutan ke 9 dari 10 keganasan terbanyak di Indonesia dengan persentase 4,43 \%. ${ }^{7}$ Pada tahun 2010-2011 ditemukan 102 kasus karsinoma tiroid di RSUP Dr M Djamil Padang. ${ }^{8}$

Diagnosis pasti dari nodul tiroid adalah dengan pemeriksaan histopatologi pada sampel hasil operasi. Pemeriksaan ini memakan waktu yang lama yakni tiga sampai tujuhhari. ${ }^{9}$ Metode pengambilan sampel cukup invasif dan membutuhkan penggunaan anastesi. Pengambilan sampel yang melalui proses operasi bedah membutuhkan sarana dan biaya yang tidak sedikit. Dokter bedah yang ahli juga dibutuhkan dalam pengambilan sampel. ${ }^{10}$

Pemeriksaan Fine Needle Aspiration Biopsy (FNAB) kelenjar tiroid merupakan langkah pertama yang dilakukan dalam mendiagnosis nodul tiroid. ${ }^{10}$ Pemeriksaan FNAB dianggap sebagai metode yang efektif untuk menentukan diagnosa nodul tiroid. Fine Needle Aspiration Biopsy dapat membedakan non neoplasma dan neoplasma tiroid. Kelebihan lain dari pemeriksaan FNAB ini adalah biayanya murah, waktu yang dibutuhkan tidak terlalu lama, tidak membutuhkan anastesi lokal dan relatif aman. Teknik FNAB ini menggunakan jarum suntik ukuran $25 \mathrm{G} .{ }^{10}$ Prosedur pengambilan sampel relatif simpel dengan waktu yang dibutuhkan kira- kira 20 menit. Pengambikan sampel dilakukan oleh dokter spesialis Patologi Anatomi yang kompeten untuk mencegah pengambilan sampel yang tidak adekuat. Pemeriksaan ini juga harus diperiksa oleh ahli Patologi Anatomi yang berpengalaman. Hasil pemeriksaan FNAB akan didapatkan maksimal dalam waktu dua hari. ${ }^{11}$ FNAB terbukti dapat mengurangi tindakan pembedahan yang tidak perlu sekitar $25 \%$ kasus dan meningkatkan penemuan kanker tiroid 30 $40 \%{ }^{12}$ Fine Needle Aspiration Biopsy juga dapat mengurangi biaya pelayanan kesehatan sampai $25 \%$. $^{13}$

Hasil studi yang dilakukan oleh Dean dan Gharib, mengemukakan sensitivitas dari FNAB $83 \%$, dan spesifitas dari FNAB $92 \%$, nilai prediksi positif $75 \%$, nilai negatif palsu $5 \% .{ }^{14}$ Pada sebuah penelitian di RSUD Dr. H. Abdul Moeloek Bandar Lampung periode 31 Agustus 2009 sampai dengan 31 Agustus 2014 akurasi pemeriksaan FNAB yaitu sensitifitas $94,44 \%$ dan spesifisitas $100 \%{ }^{15}$

Akurasi pemeriksaan dengan FNAB sebagai prosedur diagnostik nodul tiroid di RSUP Dr. M Djamil Padang belum pernah dilaporkan, oleh karena hal ini maka perlu dilakukan penelitian tentang akurasi FNAB sebagai prosedur diagnostik nodul tiroid di Laboratorium Patologi Anatomi RSUP Dr.M Djamil Padang.

\section{METODE}

Penelitian ini bersifat analitik dengan metode uji diagnostik menggunakan data sekunder di Laboratorium RSUP DR M Djamil Padang periode Januari 2016-Desember 2017.

Populasi penelitian ini adalah semua pasien dengan nodul tiroid di RSUP Dr M Djamil Padang yang dilakukan FNAB dan pemeriksaan histopatologi di Laboratorium Patologi Anatomi RSUP Dr M Djamil.

Sampel penelitian adalah bagian dari populasi yang memenuhi kriteria inklusi dan ekslusi. Kriteria inklusi penelitian ini adalah pasien dengan nodul tiroid di RSUP Dr M Djamil Padang yang dilakukan FNAB dan pemeriksaan histopatologi di Laboratorium Patologi Anatomi RSUP Dr M Djamil Padang. Kriteria eksklusi penelitian ini adalah pasien dengan nodul tiroid yang tidak dapat diinterpretasi (sampel yang tidak adekuat) 
dengan FNAB (Fine Needle Aspiration Biopsy) atau tidak melakukan pemeriksaan FNAB, pasien dengan nodul tiroid yang melakukan pemeriksaan FNAB tapi tidak melakukan pemeriksaan histopatologi dan pasien dengan nodul tiroid yang melakukan pemeriksaan FNAB dan pemeriksaan histopatologi dengan salah satu pemeriksaan tidak dilakukan di Laboratorium Patologi Anatomi RSUP Dr M Djamil Padang. Sampel yang memenuhi kriteria inklusi dan eksklusi dalam penelitian ini adalah 45 orang.

Data diperoleh dari catatan rekam medik pasien dan hasil FNAB serta histopatologi di Laboratorium Patologi Anatomi RSUP Dr M Djamil Padang. Data dianalisis menggunakan menggunakan rumus uji diagnostik untuk menghitung sensivifitas, spesifitas, nilai prediksi positif dan nilai prediksi egative dengan membandingkan hasil pemeriksaan FNAB dan pemeriksaan histopatologi sebagai gold standard.

HASIL

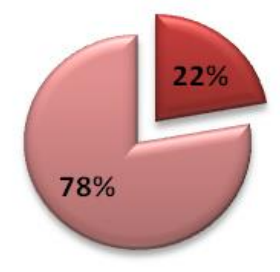

Laki-laki

$\square$ Perempuan

Gambar 1. Karakteristik jenis kelamin pasien nodul tiroid yang melakukan pemeriksaan FNAB dan histopatologi di Laboratorium Anatomi RSUP Dr. M Djamil Padang tahun 2017-2016

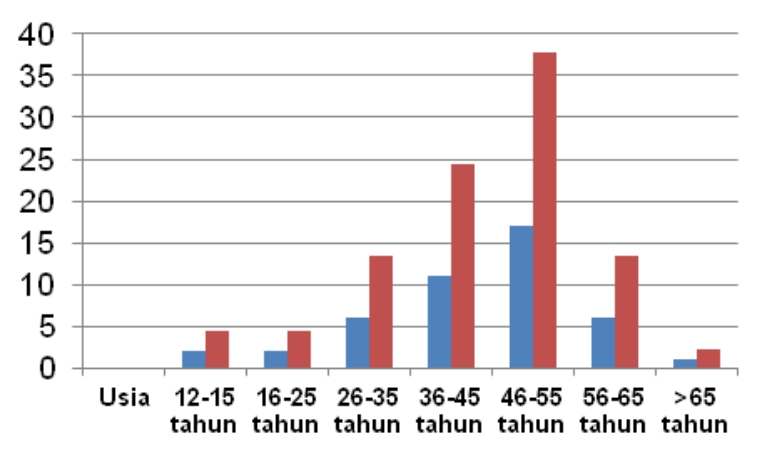

Gambar 2. Karakteristik usia pasien nodul tiroid yang melakukan pemeriksaan FNAB dan histopatologi di Laboratorium Anatomi RSUP Dr. M Djamil Padang tahun 2017-2016
Berdasarkan Gambar 1 diketahui bahwa dari 45 pasien yang menjadi subjek penelitian ini, terdapat 35 pasien perempuan $(77,78 \%)$ dan 10 pasien laki-laki $(22,22 \%)$ dari 45 kasus. Usia rerata pasien yang telah melakukan FNAB dan histopatologi tiroid selama penelitian adalah 44,11 $\pm 13,41$ tahun, dari usia 12-74 tahun. Kelompok usia paling banyak terdapat pada usia 46-55 tahun yakni 17 pasien (37,80\%). Kelompok usia paling sedikit terdapat pada usia diatas 65 tahun yakni 1 pasien (2,22\%).

Tabel 1. Hasil jenis FNAB nodul tiroid

\begin{tabular}{lll}
\hline Diagnosa & $\mathbf{n}$ & $\%$ \\
\hline Neoplasma & 15 & 33,33 \\
Folikular Neoplasma & 9 & 20,00 \\
Karsinoma Papilar & & \\
Non Neoplasma & 14 & 31,11 \\
Kista Tiroid & 7 & 15,56 \\
Adenomatous Goiter & 45 & 100 \\
\hline Total & & \\
\hline
\end{tabular}

Berdasarkan Tabel 1 diketahui bahwa dari hasil pemeriksaan FNAB 45 sampel didapatkan dua jenis neoplasma yakni folikular neoplasma dan karsinoma papilar serta dua jenis non neoplasma yakni kista tiroid daan adenomatous goiter. Folikular neoplasma memiliki jumlah terbanyak yaitu 15 sampel (33,33\%) dan dilanjutkan oleh kista tiroid dengan jumlah 14 sampel $(31,11 \%)$. Karsinoma papilar menempati urutan ketiga dengan jumlah 9 sampel (20,00\%). Adenomatous goiter dengan jumlah paling sedikit yakni 7 sampel (33,33\%).

Tabel 2. Hasil jenis histopatologi nodul tiroid

\begin{tabular}{|c|c|c|}
\hline Diagnosa & $\mathbf{n}$ & (\%) \\
\hline \multicolumn{3}{|l|}{ Neoplasma } \\
\hline Adenoma Folikular & 3 & 6,67 \\
\hline Karsinoma Papilar & 20 & 44,45 \\
\hline Karsinoma Folikular & 5 & 11,11 \\
\hline Poorly Differentiated & 1 & 2,22 \\
\hline \multicolumn{3}{|l|}{ Carcinoma } \\
\hline \multicolumn{3}{|l|}{ Non Neoplasma } \\
\hline Adenomatous & 15 & 33,33 \\
\hline \multicolumn{3}{|l|}{ Goiter } \\
\hline Tiroiditis Hashimoto & 1 & 2,22 \\
\hline Total & 45 & 100 \\
\hline
\end{tabular}


Berdasarkan Tabel 2 diketahui bahwa dari hasil pemeriksaan histopatologi 45 sampel didapatkan 4 jenis neoplasma yakni adenoma folikular, karsinoma papilar, karsinoma folikular, dan poorly differentieted carcinoma serta dua jenis non neoplasma yakni adenomatous goiter dengan tiroiditis Hashimoto.

Hasil histopatologi terbanyak adalah karsinoma papilar yaitu 20 sampel (44,45\%). Adenomatous goiter menempati urutan kedua dengan 15 sampel (33,33\%). Karsinoma folikular dengan 5 sampel $(11,11 \%)$ di urutan ketiga Adenoma Folikular dengan 3 sampel $(6,67 \%)$ di urutan keempat. Poorly differentiated carcinoma dan tiroiditis Hashimoto menempati urutan terakhir dengan masing-maing 1 sampel (2,22\%).

Hasil perbandingan FNAB dengan standar baku emasnya yaitu diagnosa histopatologi hasil operasi dari 45 kasus pasien nodul tiroid, didapatkan kasus 18 true positive, 10 kasus true negative, 11 false positive, serta 6 kasus false negative. Dari hasil di atas didapatkan uji sensitifitas sebesar $62,1 \%$, spesifisitas sebesar $62,5 \%$, nilai prediksi positif sebesar $75 \%$, nilai prediksi negatif sebesar $47,6 \%$ dan akurasi diagnosa sebesar $62,2 \%$.

\section{PEMBAHASAN}

Berdasarkan karakteristik jenis kelamin pasien nodul tiroid yang menjadi subjek penelitian ini, pasien nodul tiroid lebih banyak ditemukan pada perempuan. Angka kejadian nodul tiroid 4 kali lebih sering pada perempuan daripada laki-laki serta meningkat seiring dengan bertambahnya usia dan asupan iodium yang kurang.$^{16}$

Sebuah studi mengatakan wanita memiliki risiko yang tinggi menderita nodul tiroid karena adanya pengaruh dari hormon esterogen terhadap fungsi tiroid terutama pada periode diantara pubertas dan menopause. Wanita juga lebih rentan terhadap efek goitrogenik dari defisiensi yodium. Estrogen dianggap memiliki efek langsung pada sel tiroid manusia baik melalui mekanisme yang bergantung pada esterogen reseptor ataupun tidak dengan cara memodulasi proliferasi dan fungsi dari tiroid. ${ }^{17}$

Berdasarkan karakteristik usia pasien nodul tiroid yang menjadi subjek penelitian ini, pasien nodul tiroid lebih banyak ditemukan pada kelompok usia 4655 tahun dan paling sedikit pada kelompok usia diatas 65 tahun dengan usia rata-rata $44,11 \pm 13,41$ tahun.
Kejadian nodul tiroid dan neoplasma tiroid akan meningkat seiring dengan bertambahnya usia karena proses penuan. Pada usia 60 tahun atau lebih tua risiko pertumbuhan lebih rendah bila dibandingkan dengan usia di bawah 45 tahun. $^{18}$

Perhitungan analisis sampel didapatkan sensitivitas FNAB sebesar $62,1 \%$, spesifitas sebanyak $62,5 \%$, nilai prediksi positif sebesar $75 \%$, nilai prediksi negatif sebesar 47,6 \%, dan akurasi sebesar 62,2\%. Penelitian ini sejalan dengan penelitian yang dilakukan oleh Afroze et al tahun 2002 dengan hasil sensitivitas $61,9 \%$, spesifitas 99,3 , nilai prediksi positif $92,8 \%$,dan nilai prediksi negatif $94,7 \% .{ }^{19}$ Penelitian yang dilakukan di RSUD Soedarso Pontianak didapatkan nilai sensitivitas dan spesifisitas dari FNAB dari tahun 2006 hingga tahun 2013 bervariasi. $^{20}$ Nilai sensitivitas FNAB yang terendah adalah $50 \%$ dan yang tertinggi adalah $100 \%$. Begitu pula dengan nilai spesifisitas FNAB, yang terendah $50 \%$ dan yang tertinggi adalah $100 \%$.

Tingkat sensitivitas yang memperlihatkan kemampuan uji diagnostik untuk mendeteksi adanya penyakit atau kemungkinan bahwa hasil uji diagnostik akan positif benar (true positive) bila dilakukan pada sekelompok subjek yang sakit adalah sebesar $62,1 \%$. Oleh karena itu, dapat diketahui bahwa sensitivitas FNAB dalam penelitian ini kurang baik dalam mendiagnosa neoplasma tiroid. Dibutuhkan pemeriksaan penunjang lainnya seperti pemeriksaan radiologi. Tingkat spesifitas yang menunjukkan kemampuan uji diagnosis untuk menunjukkan subjek tidak sakit atau kemungkinan bahwa hasil uji diagnosis akan negatif bila dilakukan pada sekelompok subjek yang sehat adalah sebesar $62,5 \%$. Nilai prediksi positif yang menunjukkan probabilitas seseorang menderita penyakit bila hasil uji diagnostik positif adalah sebesar $75 \%$. Nilai prediksi negatif yang menunjukkan probabilitas seseorang tidak menderita penyakit bila hasil uji diagnostiknya negatif adalah sebesar 47,6\%. Beberapa literatur menyebutkan bahwa tingkat diagnosa negatif semu (false negative) cukup tinggi untuk beberapa seri. Risiko terbesar diagnosa negatif semu (false negative) biasanya berhubungan dengan neoplasma kistik, biasanya cystic papillary carcinoma. ${ }^{21}$ Lebih dari $40 \%$ neoplasma kistik mungkin tidak terdeteksi oleh FNAB. ${ }^{21}$ Diagnosa negatif semu (false negative) mungkin disebabkan oleh sampel yang tidak 
memadai, lokasi yang keliru, patologi rangkap (contohnya nodul non neoplasma dominan mungkin menutupi neoplasma yang lebih kecil dan tumbuh lebih menyebar) dan kesalahan interpretasi.

Penentuan diagnosis jenis nodul tiroid dengan FNAB menurut penelitian ini terdapat beberapa kesalahan, hal itu dijelaskan pada Tabel 1 yaitu pada FNAB didiagnosis dengan non neoplasma tetapi oleh pemeriksaan histopatologi adalah neoplasma. Contohnya pada pemeriksaan FNAB didapakan kista tiroid namun pada pemeriksaan histopatologi didapatkan karsinoma papilar. Hal itu dapat dipengaruhi oleh pengambilan aspirat sitologi tidak tepat.

FNAB dianggap memiliki akurasi yang tinggi dalam mendiagnosis nodul tiroid namun karena prosedur FNAB hanya menggunakan sebuah jarum sehingga aspirat yang diambil sangat mungkin akan tidak merepresentasikan keseluruhan nodul tiroid. Nodul tiroid yang lebih kecil dan berlokasi lebih dalam, untuk kasus yang sulit ditentukan lokasinya dari permukaan tubuh dapat dilakukan FNAB dengan panduan USG, untuk meningkatkan akurasi diagnosis. $^{22}$ FNAB menggunakan panduan USG mengurangi kejadian spesimen yang inadekuat 15-20\% turun ke $3-4 \%$ pada pasien. $^{23}$ FNAB menggunakan panduan USG menghasilkan hasil yang lebih baik, khususnya pada nodul dengan komponen kistik, berlokasi dibagian posterior dan sulit untuk dipalpasi. ${ }^{24}$

\section{SIMPULAN}

Akurasi diagnosa FNAB pada pasien dengan nodul tiroid di LaboratoriumPatologi Anatomi RSUP Dr. M Djamil Padang periode Januari 2016- Desember 2017 adalah sebesar 62,2\%.

Sensitivitas pemeriksaan FNAB pada pasien dengan nodul tiroid $62,1 \%$ dan spesifisitas $62,5 \%$.

Nilai prediksi positif pemeriksaan FNAB pada pasien dengan nodul tiroid adalah sebesar $75 \%$ dan nilai prediksi negatif adalah $47,6 \%$.

\section{DAFTAR PUSTAKA}

1. Dean DS, Gharib H. Epidemiology of thyroid nodules. Best Pract Res Clin Endocrinol Metab. 2008 Dec;22(6):901-11.
2. Jemal $A$, Siegel $\mathrm{R}, \mathrm{Xu}$ J, Ward E. Cancer statistics. CA Cancer JClin. 2010 Sep-Oct;60(5): 277-300.

3. Brady B. Incidence and types of thyroid cancer (diunduh Oktober 2017). Tersedia dari: http://www.endocrineweb.com/guides/thyroidcancer/incidence-types-thyroid-cancer.

4. Neki, HL Kazal. Solitary Thyroid Nodule-An Insight. JIACM 2006;7(4):328-33.

5. National Cancer Institute. Surveillance, epidemiology, and end results (SEER). SEER Stat Fact Sheets:Thyroid Cancer (diunduh Oktober 2017). Tersedia dari: http://www.seer.cancer.gov/ statfacts/html/thyro.html.

6. Nguyen QT, Lee EJ, Huang MG, Park YI, et al. Diagnosis and treatment of patients with thyroid cancer. Am Health Drug Benefits. 2015 Feb;8(1): 30-40.

7. Ramli M. Kanker tiroid, penatalaksanaan, diagnosis, dan terapi. Dalam: Ramli M, Umbas R, Panigoro SS, editor (penyunting). Deteksi dini kanker. Jakarta: Balai Penerbit FKUI. 2005.hlm.9-31.

8. Putri E, Khambri D,Rusdji SR. Hubungan daerah tempat tinggal dengan gambaran histopatologi karsinoma tiroid pada masyarakat Sumatera Barat. Jurnal Kesehatan Andalas.2014;3(2):147-50.

9. Breast Cancer Org. Test results and medical records (diunduh Oktober 2017 ). Tersedia dari: http://www.breastcancer.org/symptoms/testing/resul ts records.

10. Ruchi Mathur. Fine needle aspiration biopsy of the thyroid (diunduh November 2017). Tersedia dari: https://www.medicinenet.com/fine-needle aspiration biopsy of the thyroid/article.htm

11. Ljung BM, Hamolsky D, Tioupine E. Fine needle aspiration (FNA) biopsy patient information sheet (diunduh November 2017). Tersedia dari: http://www.cancersupportivecare.com/fna.html.

12. Furlan JC, Bedard YC, Rosen IB. Single versus sequential fine-needle aspiration biopsy in the management of thyroid nodular disease. Can J Surg. 2005 Feb;48(1):12-8.

13.Guille JT, Opoku BA, Thibeault SL, Chen H. Evaluation and management of the pediatric thyroid nodule. Oncologist. 2015 Jan;20(1):19-27. 
14.Dean DS, Gharib H. Fine-needle aspiration biopsy of the thyroid gland. Dalam: De GJ,, Chrousos G, Dungan K, editor (penyunting). Endotext. South Dartmouth (MA): MDText.com, Inc. 2002.

15.Wardani YA. Studi diagnostik Fine Needle Aspiration Biopsy (FNAB) dalam menegakkan diagnosis nodul tiroid di Instalasi Patologi Anatomi Rumah Sakit Umum Daerah Dr. H. Abdul Moeloek Bandar Lampung (skripsi). Bandar Lampung: FK Universitas Negeri Lampung ; 2015.

16. Popoveniuc G, Jonklaas J. Thyroid Nodules. Med Clin North Am. 2012 Mar;96(2): 329-49.

17. Santin AP, Furlanetto TW. Role of estrogen in thyroid function and growth regulation. J Thyroid Res. 2011; 2011:875125.

18. Crokett SS, Hershman J. Thyroid nodules and cancer in the elderly. Endotext. 2015 Mei.

19. Afroze N , Kayani N , Haasan S H. Role of fine needle aspiration cytology in the diagnosis of palapable thyroid lesions. Indian L Pathol Microbiol. 2002;45(3):241-6.
20. Kartikasari V. Sensitivitas dan spesifisitas fine needle aspiration biopsy (FNAB) pada nodul tiroid di RSUD Soedarso periode Tahun 2006-2013 (skripsi). Pontianak: Fakultas Kedokteran Universitas Tanjungpura; 2015.

21. ChangSH, Joo M, KimJ H. Fine Needle Aspiration Biopsy of Thyroid Nodules in Children and Adolescents. Korean Med Sci. 2006 Jun; 21(3): 469-73.

22. Goellner JR. Problems and pitfalls in thyroid cytology. Monogr Pathol. 1997;39:75-93.

23. Danese D, Sciacchitano S, Farsetti A andreoli M and Pontecorvi A. Diagnostic accuracy of conventional versus sonography-guided fine-needle aspiration biopsy of thyroid nodules. Thyroid. 1998;8:15-21.

24. Nguyen QT, Lee EJ, Huang MG, Park YI, Khullar A, Plodkowski RA. Diagnosis and treatment of patientswith thyroid cancer. American Health \& Drug Benefits. 2015 Feb;8(1):30-40. 